\title{
Functional, motor, and sensory assessment instruments upon nerve repair in adult hands: systematic review of psychometric properties
}

Marisa de Cássia Registro Fonseca ${ }^{1,2^{*}}$ (D), Valéria Meireles Carril Elui ${ }^{1}$, Emily Lalone ${ }^{2}$, Natália Claro da Silva ${ }^{3}$, Rafael Inácio Barbosa ${ }^{4}$, Alexandre Márcio Marcolino ${ }^{4}$, Flávia Pessoni Faleiros Macedo Ricci ${ }^{3}$ and Joy C. MacDermid ${ }^{2,5}$

\begin{abstract}
Background: Outcome after nerve repair of the hand needs standardized psychometrically robust measures. We aimed to systematically review the psychometric properties of available functional, motor, and sensory assessment instruments after nerve repair.

Methods: This systematic review of health measurement instruments searched databases from 1966 to 2017. Pairs of raters conducted data extraction and quality assessment using a structured tool for clinical measurement studies. Kappa correlation was used to define the agreement prior to consensus for individual items, and intraclass correlation coefficient (ICC) was used to assess reliability between raters. A narrative synthesis described quality and content of the evidence.

Results: Sixteen studies were included for final critical appraisal scores. Kappa ranged from 0.31 to 0.82 and ICC was 0.81. Motor domain had manual muscle testing with Kappa from 0.72 to 0.93 and a dynamometer ICC reliability between 0.92 and 0.98 . Sensory domain had touch threshold Semmes-Weinstein monofilaments (SWM) as the most responsive measure while two-point discrimination (2PD) was the least responsive (effect size 1.2 and 0.1). A stereognosis test, Shape and Texture Identification (STI), had Kappa test-retest reliability of 0.79 and inter-rater reliability of 0.61 , with excellent sensibility and specificity. Manual tactile test had moderate to mild correlation with 2PD and SWM. Function domain presented Rosén-Lundborg score with Spearman correlations of 0.83 for total score. Patient-reported outcomes measurements had ICC of 0.85 and internal consistency from 0.88 to 0.96 with Patient-Rated Wrist and Hand Evaluation with higher score for reliability and Spearman correlation between 0.38 and 0.89 for validity.

\footnotetext{
* Correspondence: marisa@fmrp.usp.br

'Department of Health Sciences, Ribeirao Preto Medical School, University of

Sao Paulo, Ribeirao Preto, SP, Brazil

${ }^{2}$ Clinical Research, Hand and Upper Limb Centre, St Joseph's Health Centre,

Western University, London, ON, Canada

Full list of author information is available at the end of the article
}

(c) The Author(s). 2018 Open Access This article is distributed under the terms of the Creative Commons Attribution 4.0 International License (http://creativecommons.org/licenses/by/4.0/), which permits unrestricted use, distribution, and reproduction in any medium, provided you give appropriate credit to the original author(s) and the source, provide a link to the Creative Commons license, and indicate if changes were made. The Creative Commons Public Domain Dedication waiver (http://creativecommons.org/publicdomain/zero/1.0/) applies to the data made available in this article, unless otherwise stated. 


\begin{abstract}
(Continued from previous page)
Conclusions: Few studies included nerve repair in their sample for the psychometric analysis of outcome measures, so moderate evidence could be confirmed. Manual muscle test and Rotterdam Intrinsic Hand Myometer dynamometer had excellent reliability but insufficient data on validity or responsiveness. Touch threshold testing was more responsive than 2PD test. The locognosia test and STI had limited but positive supporting data related to validity. Rosén-Lundborg score had emerging evidence of reliability and validity as a comprehensive outcome following nerve repair. Few questionnaires were considered reliable and valid to assess cold intolerance. There is no patient-reported outcome measurement following nerve repair that provides comprehensive assessment of symptoms and function by patient perspective.
\end{abstract}

Keywords: Hand injuries, Validity of tests, Evaluation, Outcome, Systematic review

\section{Background}

Traumatic nerve injuries in the hand are common and can result in chronic dysfunction, extensive rehabilitation, and repeated surgeries. These injuries have a higher incidence in young males [1-3]. The combination of residual disability at a young age has a profound economic lifelong impact through the impacts on work ability. Additionally, impairment and disability after nerve injury result in reduced quality of life [4-6]. Previous studies have shown that, as the complexity of the case increases, the cost and duration of treatment also increases [2, 7, $8]$. When the trauma to the hand is poorly managed either during surgery or rehabilitation, it is not only the patient, but also the whole family that suffers [9].

Patients with peripheral nerve injuries that affect the hand need specialized surgery and rehabilitation to regain function [10]. Nerve injuries can affect mobility and sensibility leading to cold sensitivity and pain [11]. A previous systematic review of nerve repair techniques determined that patient's age, tension of repair, time of repair, level of injury, and scar formation following surgery affect the prognosis for functional outcome [12]. Nevertheless, some degree of persistent posttraumatic disability often persists after nerve laceration and repair [4]. Therefore, assessing patient with a valid outcome method or instruments following nerve repair is essential as it provides information about patients' sensorimotor deficits and function [1,13-16] and is critical to developing best evidence in repair and rehabilitation.

Since Tinel [17], many authors have described several approaches related to functional assessment after nerve lesion and repair [18-23]. These range from an ordinal "numerical grading system" based on a motor and sensory scale $[18,20]$ to a multi-dimensional comprehensive scale based on sensory, motor, and pain domains in a model instrument for documentation of outcome after nerve repair $[24,25]$, and a variety of other instruments [14, 16, 26-29].

Selecting an instrument or a battery of tests for assessment of nerve outcomes requires knowledge of the clinical measurement properties of the potential test options. Ideally, the selected measurement should be reliable and be able to distinguish functional outcomes, measure change in clinical status, and predict the outcome of different interventions [21, 23, 26, 30-32]. Based on principles of evidence-based practice [33-36], any outcome measurement [11, 31-33], including those for peripheral nerve repair assessment, it is essential to know the psychometric $[37,38]$ properties such as reliability, validity, and responsiveness [30, 38, 39]. Reliability is also referred to as reproducibility, stability, repeatability, variability, consistency, concordance, dependability, precision, and agreement [40-42]. It is the degree to which the measurement is free of error, depending on the specific measurement instrument, persons performing the measurement, patients, and circumstances under which the measurement is taken. A repeated measurement over time is called test-retest, by different persons on the same occasion is called inter-rater, or by the same persons on different occasions is called intra-rater. Reliability can be assessed over different intervals or raters and by a variety of different statistical methods [37, 42]. Validity is the measurement property that defines the extent to which an instrument measures the construct it aims to measure (truthfulness). There are a variety of types of validity reflecting the different purposes of clinical measurement and different techniques for assessing the extent to which a measure can fulfill these purposes. The main types of validity are content validity related to relevance and comprehensiveness, criterion validity (concurrent and predictive) which relates to a gold standard or criterion referent measure, and construct validity (structural validity, discriminative, convergent, divergent and cross-cultural validity). A variety of statistical methods can be applied to assess these properties. Responsiveness (longitudinal validity) is a property of an instrument, which detects changes in the construct over time [42, 43], and is also has a range of statistical techniques designed to assess the extent and classification accuracy of change that occurs due to time or intervention.

Jerosch-Herold [44] published a systematic review focused just on sensory tests for nerve repair assessment in 2005 , and at that time, there were few instruments 
with sufficient evidence related to the reliability, validity, and responsiveness of tests to assess sensibility after nerve repair [43, 45]. Since evidence accumulates over time and nerve outcome measures should extend beyond sensation, there was a need to conduct a broader and more current review of nerve repair outcome measures. The objective of this study was therefore to systematically review and summarize available evidence on the clinical measurement properties of instruments, which evaluate motor, sensory, and functional status after primary or secondary nerve repair in adult hands using a standardized critical appraisal tool of quality for psychometric articles and multiple independent appraisers.

\section{Methods}

This is a systematic review of health measurement instruments. A literature search was conducted using the following databases: PubMed/MEDLINE, SCOPUS, Cochrane Library, PEDro, CINAHL, PsychInfo, EMBASE, SciELO, LILACS, SPORTDiscus, ERIC, and Google Scholar, ranging from 1966 to 2017. The search was limited to publications, written in English, Spanish, or Portuguese.

Keywords used included "hand" or "hand injuries" or "injury" and ("peripheral nerve injury" or "peripheral nerve repair" or "nerve repair" or "nerve injury") and ("outcome" or "outcome assessment" or "assessment" or "instrument" or "tool" or "functional outcome" or "documentation" or "evaluation") and ("reliability" or "responsiveness" or "validity" or "validation" or "psychometrics") and ("clinical measurements" or "Rasch analysis" or "factor analysis" or "cross cultural translation").

\section{Selection for inclusion}

Studies were included if they addressed at least one psychometric property, related to motor impairment, sensory status, cold intolerance, pain, or functional status from primary or secondary nerve repair at any level on the forearm, hand, fingers, and/or wrist. These instruments included any device developed to measure motor and sensory function, but also cold intolerance or pain outcome or functional status.

Articles were excluded in our final review if they met any of the following criteria: descriptive, epidemiologic, or interventional studies; pediatric participants or adults with neuromuscular diseases or any other disorder of central nervous system or even generic outcomes to trauma not specifically related to nerve repair in the hand; and unpublished, conference proceeding, thesis, and dissertation and non-human studies.

The initial selection, based on titles and abstracts, was performed by one reviewer and reviewed by the second to identify any potentially relevant articles that have been missed in the original screening (Fig. 1). If there was any uncertainty of eligibility for inclusion, the full text was obtained for the final decision about inclusion. The study authors independently performed quality appraisal on each of the included papers, then met to compare ratings and discuss any discrepancies. Pairs of raters, using a structured appraisal tool [46] and its interpretation guide (Table 1), conducted the data extraction and review process. Kappa correlation was used to define the agreement prior to consensus for individual items, and intraclass correlation coefficient (ICC) was used to assess reliability between the raters, by SPSS $^{\text {тा }}$, version 20.0. This systematic review was not registered on PROSPERO but was reported in accordance with the Preferred Reporting Items for Systematic Reviews and Meta-analysis (PRISMA) statement (Additional file 1 Appendix) and COSMIN [42].

\section{Results}

Eighty full papers were selected for initial evaluation. At that phase, 64 papers were also excluded because they did not address to nerve injury by trauma. So, sixteen papers were ultimately included for critical appraisal and data extraction. Descriptive syntheses of the study population and sample, as well as a description of the instrument and its examined psychometric properties, are summarized in Table 2.

Data extraction was performed based on the MacDermid's Guide of Critical Appraisal of Study Quality for Psychometric Articles [46]. Overall, the quality of each paper was variable, ranging from 11 to 22 out of maximum 24 , although most of them (15) reached or exceeded at least $50 \%$ on the quality score rating (Table 3 ). Weighted kappa was calculated by a pre-consensus inter-rater agreement method on the 12 individual items of critical appraisal [46] ranging from 0.31 to 0.82 . The ICC of total scores was 0.81 , ranging from 0.38 to 0.94 between the two raters.

\section{Reliability}

Reliability was the most frequently reported psychometric property for instruments that assessed muscle strength, sensory tests, functional tests, and patient-report questionnaires after nerve repair.

Manual strength test for nerve repair and leprosy disease had an intra-examiner Cohen's weighted Kappa between 0.71 and 0.96 and inter-examiner of 0.72 to 0.93 [47]. A dynamometer specially designed for intrinsic muscle assessment had intraclass coefficient (ICC) index between 0.94 and 0.98 and SEM (standard error of measurement) between 2.2 and 5.8 [48]. The patient-reported outcomes measurements (PROMS), Cold Intolerance Symptom Severity (CISS), Cold Sensitivity Severity (CSS), Potential Work Exposure Scale (PWES) [49], Patient Evaluation Measure (PEM) [50], Michigan Hand Outcome Questionnaire (MHQ) [50], disabilities of the arm, shoulder and hand (DASH) [50, 51], hand assessment tool (HAT), Health 


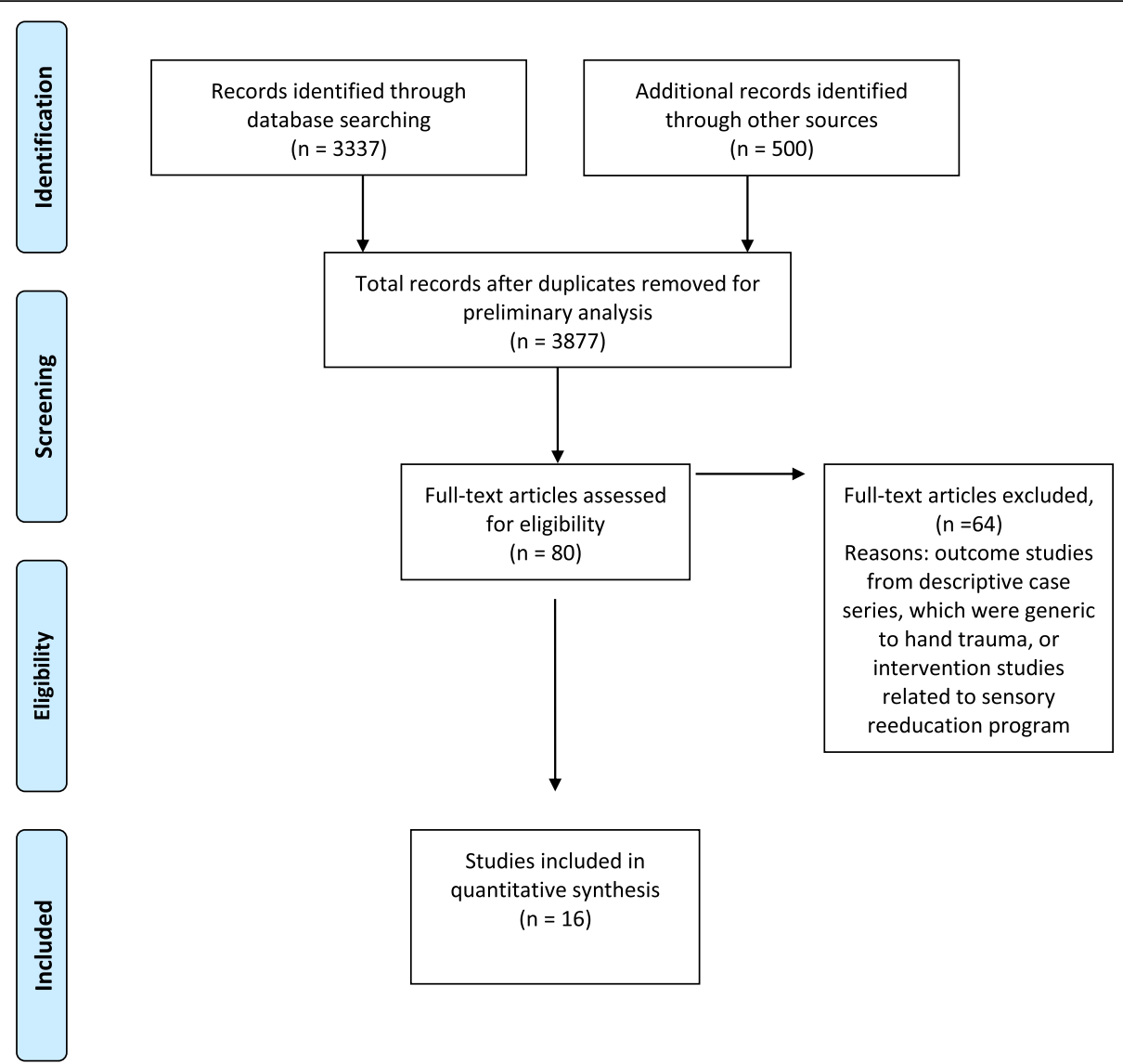

Fig. 1 PRISMA flow chart for search strategy

Survey (Short Form 12) (SF12) [52], Patient-Rated Wrist and Hand Evaluation (PRWHE) [53], and the simplified Chinese version of DASH (DASH-CHNPLAGH) [51] had high internal consistency ranging from 0.88 to 0.96 with higher value for DASH 0.98 [50]. PRWHE was analyzed by Rasch analysis and supports internal consistency of the scale $(\alpha=0.96)$ and reliability (as measured by the person separation index) of 0.95 . The analysis on this paper supported a three-subscale structure (pain, specific activities, and usual activities) rather than the current divisions of pain and disability for this questionnaire, based on item response theory rather than classical test theory [53]. The CISS, CSS, and PWES PROMS had ICC of 0.85 [49]. A battery of sensory tests had moderate to high Pearson correlation coefficient reliability index $(-0.47-0.90)$ [47]. The locognosia test had high test-retest ICC for median (0.92) and ulnar (0.85) nerve [54]. STI test ${ }^{\mathrm{Tw}}$ (Shape and Texture Identification test) was shown to have a test-retest weighted Kappa value of 0.79 , an internal consistency Cronbach's alpha of 0.78 [55], and an inter-tester score of 0.66 [56].

\section{Validity}

The cold sensitivity PROM had a Spearman's correlation of 0.73 for CISS and 0.67 for CSS for construct validity analysis, and for content validity, it was found that $92 \%$ of patients answered the questionnaires [49]. The PEM, MHQ, and DASH PROMS had a Pearson's correlation coefficient of $>0.38$ [50]. Naidu et al. [52] analyzed 94 injuries, only one of which was a nerve repair, and reported 0.89 for Pearson's correlation (construct validity). Chen et al. [51] correlated the Chinese version of DASH with SF-36 items and showed a negative correlation and positive correlation with a visual analogue scale (VAS).

The Pearson's correlation was moderate to high $(r=$ $0.90-0.47)$ for a battery of sensory tests [47]. The locognosia test had an effect size of 1.2 for median and 1.3 for ulnar nerve [57]. STI test ${ }^{\text {tix }}$ presented sensitivity of 1.0 and specificity of 0.90 [55]. The Rosén-Lundborg score [24] had good to excellent results for its sub-domains for Spearman rank correlations. Manual tactile test (MTT) designed to assess functional aspects of Carpal tunnel syndrome including barognosis, stereognosis, and roughness discrimination tests had moderate concurrent validity for early sensory functional results in a nerve repair sample [58].

\section{Responsiveness}

Responsiveness was tested only in two studies [57, 59]. Jerosch-Herold [57] analyzed in a battery of tests the 
Table 1 Critical appraisal of study quality for psychometric articles: evaluation form [46]

\begin{tabular}{|c|c|c|}
\hline Authors: & Year: & Rater: \\
\hline \multirow[t]{2}{*}{ Evaluation Criteria } & & Score \\
\hline & & 2 \\
\hline
\end{tabular}

Study question

1. Was the relevant background work cited to define what is currently known about the measurement properties of measures under study, and the potential contributions of the current research question to inform that knowledge base?

Study design

2. Were appropriate inclusion/exclusion criteria defined?

3. Were specific clinical measurement questions/hypotheses identified?

4. Was an appropriate scope of measurement properties considered?

5. Was an appropriate sample size used?

6. Was appropriate retention/follow up obtained?(for studies involving retesting; otherwise $\mathrm{n} / \mathrm{a}$ )

Measurements

7. Were specific descriptions provided of the measure under study and the method(s) used to administer it?

8. Were standardized procedures used to administer all study measures in a manner that minimized potential sources of error/bias (including the study measure and its comparators?

Analyses

9. Were analyses conducted for each specific hypothesis or purpose?

10. Were appropriate statistical tests performed to obtain point estimates of the measurement properties?

11. Were appropriate ancillary analyses done to quantify the confidence in the estimates of the clinical measurement property (Precision/Confidence Intervals, benchmarks comparisons, standard error of measurement/ROC curves, alternate forms of analysis like SEM/MID,etc)?

Recommendations

12. Were clear, specific and accurate conclusions made about the clinical measurement properties; that were associated with appropriate clinical measurement recommendations and supported by the study objectives, analysis, and results?

Subtotals(columns 1 and 2)

Total score \% (sum of subtotal/ $24 \times 100$ ), or, if for a specific paper or topic an item is deemed inappropriate, then you can sum of items, divide by 2 times the number of items, and multiply by 100 to get the percentage score

OMacDermid 2011

standard response mean (SRM) and effect size and found the WEST ${ }^{\mathrm{Tm}}$ to be the most responsive sensibility test $(\mathrm{SRM}=2.4$, effect size $=1.2)$ and also found that the 2PD (two-point discrimination) test was less responsive $(\mathrm{SRM}=0.4$, effect size $=0.1)$. Rosén and Jerosh-Herold [59] reported a SRM of 0.73 and a flooring effect for the STI test ${ }^{\mathrm{Tm}}$ in relation to $2 \mathrm{PD}$ comparing patients in baseline and after 6 months of nerve repair.

\section{Discussion}

Clinical measurement related to motor and sensory assessment after nerve repair was found to have excellent reliability but not sufficient evidence in terms of validity or responsiveness.

Reliability was most commonly assessed using test-retest $[47,49,50,52,54,55,60]$. A lesser number addressed inter-tester [55], intra-tester [60], and inter-instrument [48] reliability. All the papers that included internal consistency in their analyses linked this psychometric property to reliability and not to validity $[55,49,50,52$, 53]. This is a common practice; although since internal consistency reflects the correlation between items, it is related to structural validity.

Validity was analyzed using content [55, 49], construct $[47,55,48-52,55,61]$, and concurrent [58] approaches for assessment. Criterion validity was assessed by Rosén and Lundborg [55] for the STI test ${ }^{\mathrm{mix}}$. Only one study presented data of a PROM based on item response theory, rather than classical test theory [53].

Responsiveness was tested in only two studies $[59,57]$ addressing nerve repair which found static $2 \mathrm{PD}$ to be the least responsive. Although simple and easily applicable and used as reference to the modified highest classification [62] in many digital nerve repair studies [63, 64], this device has been criticized as having a low standardization as a tactile gnosis test without a performance protocol description present $[62,65]$. 
Table 2 Summary of studies addressing psychometrics properties of the outcomes instruments for nerve repair

\begin{tabular}{|c|c|c|c|c|}
\hline Study & $N$ & Population & Instrument & Psychometrics properties \\
\hline $\begin{array}{l}\text { Jerosch- } \\
\text { Herold [47] }\end{array}$ & 14 & $\begin{array}{l}14 \text { median } \\
\text { nerve injuries }\end{array}$ & $\begin{array}{l}\text { Set of sensory tests: S2PD, M2PD, LOCAL, Modified Pickup test } \\
\text { Moberg, Object recognition, ADL }\end{array}$ & Reliability, validity \\
\hline $\begin{array}{l}\text { Brandsma } \\
\text { et al. [60] }\end{array}$ & 28 & $\begin{array}{l}\text { Leprosy disease } \\
\text { and nerve } \\
\text { injuries }\end{array}$ & $\begin{array}{l}\text { Manual muscle strength test for specific movements related to } \\
\text { hand intrinsic muscles }\end{array}$ & Reliability: inter/intraobserver \\
\hline Rosén [61] & 25 & $\begin{array}{l}15 \text { median, } 10 \\
\text { ulnar nerve } \\
\text { injuries }\end{array}$ & $\begin{array}{l}\text { Set of tests: sensory function /perception of touch/vibration: } \\
\text { Semmes-Weistein Monofilaments, vibrations of } 30 \text { and } 256 \mathrm{~Hz} \text {; } \\
\text { Tactile gnosis: localization of constant and moving touch, } \\
\text { S2PD, M2PD, shape-identification test; motor function tests: } \\
\text { dynamometer; integrated sensory and motor function tests: } \\
\text { Modified Pickup test Moberg, Sollerman grip test; cold intoler- } \\
\text { ance test and hypersensitivity (qualitative); neurophysiological } \\
\text { tests: electroneurography, electromyography }\end{array}$ & Construct validity \\
\hline $\begin{array}{l}\text { Rosén } \\
\text { Lundborg } \\
\text { [55] }\end{array}$ & 54 & $\begin{array}{l}26 \text { median, } 19 \\
\text { ulnar, } 7 \\
\text { combined }\end{array}$ & STI test ${ }^{\mathrm{TM}}$ & $\begin{array}{l}\text { Reliability: test-retest, internal } \\
\text { consistency, validity }\end{array}$ \\
\hline $\begin{array}{l}\text { Rosén, } \\
\text { Jerosh- } \\
\text { Herold [59] }\end{array}$ & 32 & $\begin{array}{l}32 \text { median and/ } \\
\text { or ulnar }\end{array}$ & $\mathrm{S} 2 \mathrm{PD}, \mathrm{STI}$ test ${ }^{\mathrm{TM}}$ & Responsiveness \\
\hline $\begin{array}{l}\text { Rosén, } \\
\text { Lundborg } \\
\text { [24] }\end{array}$ & 70 & $\begin{array}{l}34 \text { median, } 27 \\
\text { ulnar, } 9 \\
\text { combined }\end{array}$ & $\begin{array}{l}\text { Rosén-Lundborg score (sensory, motor and pain/discomfort } \\
\text { domains) }\end{array}$ & $\begin{array}{l}\text { Reliability: test-retest, internal } \\
\text { consistency, construct validity } \\
\text { (concurrent) }\end{array}$ \\
\hline $\begin{array}{l}\text { Jerosch- } \\
\text { Herold [57] }\end{array}$ & 115 & $\begin{array}{l}23 \text { median and } \\
\text { ulnar nerve } \\
\text { injuries }\end{array}$ & $\begin{array}{l}\text { Set of sensory tests: WEST, S2PD, M2PD, LOCAL, modified } \\
\text { pickup test Moberg, object recognition }\end{array}$ & Responsiveness \\
\hline Rosén [56] & 91 & $\begin{array}{l}35 \text { median, } 23 \\
\text { ulnar }\end{array}$ & STI test ${ }^{T M}$ & Reliability: inter-tester \\
\hline $\begin{array}{l}\text { Schreuders } \\
\text { et al. [48] }\end{array}$ & 27 & $\begin{array}{l}11 \text { median, } 9 \\
\text { ulnar, } 7 \\
\text { combined }\end{array}$ & $\mathrm{RIMH}^{\mathrm{TM}}$ & Reliability \\
\hline $\begin{array}{l}\text { Jerosch- } \\
\text { Herold et al. } \\
{[54]}\end{array}$ & 39 & $\begin{array}{l}23 \text { median and } \\
16 \text { ulnar nerve } \\
\text { injuries }\end{array}$ & Locognosia test & $\begin{array}{l}\text { Reliability: test-retest, construct validity } \\
\text { (discriminant) }\end{array}$ \\
\hline $\begin{array}{l}\text { Carlsson et } \\
\text { al. [49] }\end{array}$ & 159 & $\begin{array}{l}54 \text { nerve } \\
\text { injuries }\end{array}$ & 3 cold sensitivity questionnaires: CISS,CSS,PWES & $\begin{array}{l}\text { Reliability: test-retest, internal } \\
\text { consistency, content and construct } \\
\text { validity }\end{array}$ \\
\hline $\begin{array}{l}\text { Dias et al. } \\
\text { [50] }\end{array}$ & 100 & $\begin{array}{l}26 \text { nerve } \\
\text { injuries( } 1 \text { ulnar, } \\
25 \text { median) }\end{array}$ & 3 questionnaires: PEM, MHQ, DASH & $\begin{array}{l}\text { Reliability: reproducibility/test-retest, } \\
\text { internal consistency, construct validity }\end{array}$ \\
\hline $\begin{array}{l}\text { Naidu et al. } \\
\text { [52] }\end{array}$ & $\begin{array}{l}94 \text { hand } \\
\text { and wrist } \\
\text { problems }\end{array}$ & 1 nerve injury & HAT, DASH, SF12 & $\begin{array}{l}\text { Reliability: test-retest, internal } \\
\text { consistency, construct validity (con- } \\
\text { vergent and discriminant) }\end{array}$ \\
\hline $\begin{array}{l}\text { Packham, } \\
\text { MacDermid } \\
\text { [53] }\end{array}$ & 264 & $\begin{array}{l}14.4 \% \text { nerve } \\
\text { injury/repair }\end{array}$ & PRWHE and subscales & Test-retest reliability and content \\
\hline $\begin{array}{l}\text { Chen et al. } \\
\text { [51] }\end{array}$ & 300 & $\begin{array}{l}7 \text { median, } 6 \\
\text { ulnar, } 9 \text { radial } \\
\text { nerve }\end{array}$ & DASH-CHNPLAGH & $\begin{array}{l}\text { Translation and cultural adaptation, } \\
\text { test-rest reliability and construct } \\
\text { validity }\end{array}$ \\
\hline $\begin{array}{l}\text { Hsu et al. } \\
{[58]}\end{array}$ & 30 & $\begin{array}{l}04 \text { median, } 11 \\
\text { digital nerve }\end{array}$ & MTT, SWM, S2PD, M2PD & Concurrent validity \\
\hline
\end{tabular}

CISS Cold Intolerance Symptom Severity, CSS Cold Sensitivity Severity, PWES Potential Work Exposure Scale, PEM Patient Evaluation Measure, MHQ Michigan Hand Outcome Questionnaire, DASH disabilities of the arm, shoulder and hand, DASH-CHNPLAGH simple Chinese version of DASH, PRWHE Patient-Rated Wrist and Hand Evaluation, S2PD static two-point discrimination, M2PD moving two-point discrimination, LOCAL area localization, ADL activities of daily living, WEST touch threshold test, HAT hand assessment tool, SF12 Health Survey (Short Form 12), STI test ${ }^{\mathrm{TM}}$ Shape and Texture Identification test, RIMH ${ }^{\mathrm{TM}}$ Rotterdam Intrinsic Hand Myometer, MTT manual tactile test 
Table 3 Results of quality of studies on the psychometric properties of instruments for sensory and motor assessment after nerve repair based on "Critical Appraisal of Study Quality for Psychometric Articles: Evaluation Form" [46]

\begin{tabular}{llllllllllllllll}
\hline Study & 1 & 2 & 3 & 4 & 5 & 6 & 7 & 8 & 9 & 10 & 11 & 12 & Total & Percent \\
\hline Jerosch-Herold [47] & 2 & 2 & 0 & 1 & 0 & NA & 2 & 1 & 1 & 1 & 0 & 1 & 11 & 45.8 \\
Brandsma et al. [60] & 1 & 1 & 1 & 1 & 0 & 2 & 2 & 2 & 2 & 2 & 0 & 1 & 15 & 62.5 \\
Rosén [61] & 2 & 2 & 0 & 1 & 0 & NA & 2 & 2 & 2 & 2 & 0 & 2 & 15 & 62.5 \\
Rosén and Lundborg [55] & 2 & 2 & 2 & 2 & 0 & 2 & 2 & 2 & 2 & 1 & 2 & 2 & 21 & 87.5 \\
Rosén and Jerosh-Herold [59] & 2 & 2 & 2 & 0 & 0 & 2 & 1 & 2 & 2 & 2 & 1 & 2 & 18 & 75 \\
Rosén and Lundborg [24] & 2 & 1 & 0 & 1 & 0 & NA & 2 & 1 & 1 & 1 & 1 & 2 & 12 & 50 \\
Jerosch-Herold [57] & 1 & 2 & 0 & 0 & 0 & 1 & 2 & 2 & 2 & 2 & 1 & 2 & 15 & 62.5 \\
Rosén [56] & 2 & 1 & 2 & 0 & 0 & NA & 1 & 1 & 2 & 2 & 2 & 2 & 15 & 62.5 \\
Schreuders et al. [48] & 2 & 1 & 0 & 0 & 0 & NA & 2 & 2 & 2 & 2 & 0 & 2 & 13 & 54.2 \\
Jerosch-Herold et al. [54] & 2 & 1 & 2 & 1 & 0 & NA & 2 & 2 & 2 & 1 & 2 & 2 & 17 & 70.8 \\
Carlsson et al. [49] & 2 & 2 & 2 & 2 & 0 & 1 & 1 & 1 & 2 & 1 & 1 & 2 & 17 & 70.8 \\
Dias et al. [50] & 1 & 2 & 0 & 2 & 0 & 2 & 1 & 1 & 2 & 1 & 2 & 1 & 15 & 62.5 \\
Naidu et al. [52] & 1 & 2 & 0 & 2 & 0 & 1 & 2 & 2 & 2 & 1 & 1 & 2 & 16 & 66.7 \\
Packham and MacDermid [53] & 2 & 1 & 2 & 2 & 2 & NA & 2 & 2 & 2 & 2 & 2 & 2 & 21 & 95.4 \\
Chen et al. [51] & 2 & 1 & 1 & 2 & 2 & 2 & 2 & 2 & 2 & 2 & 2 & 2 & 22 & 91.6 \\
Hsu et al. [58] & 1 & 1 & 1 & 1 & 1 & 1 & 2 & 2 & 1 & 2 & 0 & 1 & 14 & 58.3 \\
\hline
\end{tabular}

Item evaluation criteria of critical appraisal tool. NA not applicable

The most common limitation found in this review was a lack of sample size calculation and a small amount of specific nerve repair volunteers inside the total sample in the studies included. As well, few studies described the tests, examiners, and procedures adequately. Since these are critical to fidelity of the assessment techniques, this can affect implementation of standardized methods in practice.

Two reviewers performed the selection of papers and critical appraisal. The other reviewers checked all the decisions. However, there were difficulties to identify and select the studies based on the samples, which should fulfill the inclusion criteria strictly related to nerve repair after trauma.

Clear presentation of clinical measurement objectives was often absent in the studies, which would benefit from better structure in terms of design and integration of methods, results, and discussion. Exceptions to those were the studies that assessed reliability and validity such as Carlsson et al. [49] who analyzed three different cold sensitivity PROMS questionnaires, Dias et al. [50] who compared three questionnaires for hand trauma including nerves, Jerosh-Herold [54] who analyzed median nerve repair in a battery of sensory tests, and Jerosh-Herold et al. [54] in other study that found excellent reliability and validity for locognosia test in peripheral nerve injuries of the hand.

Rosén and Lundborg [55] tested the STI test ${ }^{\mathrm{tm}}$ as a new tactile gnosis instrument; Naidu et al. [52] developed a PROM for patients with injuries of hand and wrist including nerve injury. Rosén and Lundborg [24] developed and described the model instrument for the documentation of outcome after nerve repair. These represent the newest dedicated outcome measures for nerve repair. While they are promising, the number of studies examining them is insufficient [65-67]. Future studies validating these tools are needed.

Two main forms of assessment of motor function were found in the selected studies: one involving the manual function muscle test [60] and the other dynamometers specially developed to assess the intrinsic muscles of the hand [48]. Brandsma et al. [60] analyzed the well-known manual muscle strength test focused on movement of hand intrinsic muscles in leprosy and nerve injuries patients and found excellent inter- and intra-observer reliability. Schreuders et al. [48] analyzed the Rotterdam Intrinsic Hand Myometer (RIHM ${ }^{\mathrm{sm}}$ ) to assess isometric intrinsic muscle strength for the hand and found excellent reliability. Manual muscle testing and dynamometers are frequently used by therapists and surgeon members of the Hand Societies of Surgery and Therapy throughout the world, for muscle testing [23, 68-71], but few have studied specifically patients with nerve injury and repair [70]. Few muscle strength studies presented data related to the quantification of intrinsic hand muscles, which measures motor dysfunction directly related to the median and ulnar nerve repair in the hand. Xu et al. [71] presented the Peg Restrained Intrinsic Muscle Evaluator (PRIME) but only for children. Normative results indicated that gender and age were 
significant predictors of strength and the device was considered a reliable tool for the quantification of intrinsic hand muscle strength in children. Jacquemin et al. [72] analyzed hand intrinsic muscle strength in relation to spinal cord injury (SCI) and other myelopathies to allow early diagnosis of neurologic decline. They used a handheld myometer in healthy volunteers and patients with SCI and found good inter-rater reliability. Bohannon and Andrews also found good inter-rater reliability of a handheld dynamometer testing procedure for neurologically involved patients with different conditions including hand muscles [73].

Shieh et al. [74] discussed the impact of nerve injury on sensorimotor control by exploring the effects of nerve regeneration on the control of pinch force in executing functional tasks in patients with median nerve repairs. The results revealed significant differences in the parameters of peak pinch force, baseline pinch force, force ratio, and the percentage of maximal pinch force output at different points in the course of nerve regeneration.

Callahan [69] classified the sensibility assessment for nerve lacerations into four categories: threshold test, functional tests, objective tests, and provocative tests. Threshold tests included touch-pressure threshold testing such as Semmes-Weinstein monofilaments (SWM) [16] to determine the minimum stimulus perceived by the patient and by measuring sensory impairment [69]. Functional tests included assessments of sensibility and disability, which were caused by sensory impairment and are considered integrative tests because they require higher levels of sensory processing than the thresholds [69]. The glabrous skin of the hand has sensory receptors, which allow the perception of sensory stimuli from periphery to central nervous system. A reliable and valid battery of tests must assess this perception in a different way for compression and following nerve injury, considering the characteristics of each measurement [22]. We found in this systematic review four studies $[47,54,57$, 61 ] that analyzed a battery of tests to find reliability, validity, and responsiveness of the instruments commonly used by therapists in clinical practice to assess functional outcomes including sensibility after peripheral nerve injury and repair in the hand. The quality of these studies based on the critical appraisal tool [46] was between 45.8 and $70.8 \%$ (scores 11-17). These studies suggested that reliable and valid assessment of re-innervation could be determined using SWM, and static 2PD for the tactile gnosis assessment [61]. Jerosch-Herold in 1993 [47] tested also a battery of tests in median nerve injuries but was unable to recommend specific sensibility tests that could be valid and suggested the inclusion of functional assessment for these patients. Jerosch-Herold in 2003 [57] found the WEST to have the highest responsive and the 2PD to be the least responsive in a battery of tests. Jerosch-Herold et al. in 2006 [54] analyzed locognosia through a standard protocol using SWM based on a localization hand chart divided in zones, first described by Winn-Parry, with ratio of scores between 0 and 10 ( 2 for correct localization, 1 for immediately adjacent, and otherwise zero). They found excellent test-retest reliability (ICC 0.92 for median and ICC 0.85 for ulnar nerve repair patients) and good construct validity (discriminant) based on the magnitude of difference between affected and unaffected hand (11.1 for median and 4.7 for ulnar nerve patients) with effect size respectively 1.2 and 1.3 .

The STI test ${ }^{\mathrm{mi}}$ is an instrument developed by a research group in Sweden to assess tactile gnosis or the ability to identify shapes and textures without vision [55]. The developers found good test-retest reliability [55], good inter-tester reliability [56], and excellent criterion validity [55] related to this device for nerve injuries. The responsiveness was also good [59] and concluded that it could be used as an alternative to $2 \mathrm{PD}$ test. The MTT test was validated for a sample with nerve repair, although at an initial nerve regeneration phase [61]. As a sensory discriminative test, better responses usually will only occur after 6 months, in the dependency of axon regeneration and reinnervation on sensory receptors.

This review did not found any PROM specially developed for nerve repair outcome assessment. The HAT questionnaire developed by Naidu et al. [52] has been shown to be reliable and to measure the limitations of the hand and wrist after trauma and correlated well with the DASH and SF12 questionnaires, but it was validated for a small sample size which included only one case of nerve repair. Therefore, generalizations cannot be made based on those findings. Dias et al. [50] compared the reliability, validity, and ease of use of three PROMS: the PEM (Patient Evaluation Measure), the MHQ (Michigan Hand Outcome Questionnaire), and the DASH (disabilities of the arm, shoulder and hand) for hand disorders in which the sample included median and ulnar nerve repair. All were considered reliable, and their findings suggested that the PEM was the easiest to use; however, they could not confirm any kind of validity.

Van de Ven-Stevens et al. [75] reviewed the literature on the clinimetric properties of 23 instruments to asses hand's activity limitation, based on the relevance of hand injuries. They analyzed reliability, validity, and responsiveness, as in functional tests and as in PROMS. Results from this study found that only five instruments adequately described the psychometric properties, but none of them had a positive rating. Galanakos et al. [76] in their systematic review highlighted the challenges in developing a clinical protocol based on a valid, reliable, and responsive prognostic model, that allow more 
effective determination of which patients have a better or diminished chance for a successful motor and sensory recovery after median or ulnar nerve injury on the upper extremity.

Nerve injuries cause pain, dysthesias, and cold intolerance symptoms that combined with impairments in motor and sensory function, which contribute to loss of hand function. The model instrument for documentation after nerve repair is described by Rosén and Lundborg [24] as an instrument which represents a combination of selected items grouped in motor (motor innervation and grip strength), sensory (sensory innervation, tactile gnosis, and finger dexterity) and pain and discomfort (hyperesthesia and cold intolerance) subdomains that together get a score for the peripheral nerve, ranging from 0 to 3 . It is an effort to combine functional outcomes following nerve repair in a visual and quantitative way, developed essentially for median and ulnar nerve repair. While preliminary evidence supports multiple measures, the number, quality, and scope of current literature are insufficient to strongly recommend any specific strategy. However, given the conceptual specificity and early measurement properties, we recommend the use of the Rosén and Lundborg scale [24] for further validation and inclusion in nerve repair outcomes research.

Few studies in this review addressed the development of specific new PROMS or instruments based on COSMIN [77] to assess impairment and dysfunction related to nerve injury linked to a broader perspective, based on the International Classification of Functioning, Disability and Health (ICF). This classification, in a clinical context, could link the body functions and structures as motor and sensory domains, and the activity and participation as function domain through patient perspective by patient-rated outcome measures [34, 35].

PROMS that measures disability with subsequent validation analysis should be included in future nerve repair studies related to functional outcomes.

\section{Conclusion}

For the motor domain, both manual muscle test and a dynamometer specially developed to measure strength of intrinsic muscles of the hand had excellent reliability but were not tested for validity and responsiveness in nerve repair.

For sensory domain assessment, the SWM was the most and $2 \mathrm{PD}$ the least responsive.

A battery of tests is suggested as more reliable and valid for nerve repair assessment.

Locognosia test seems to be valid, and the STI test ${ }^{\mathrm{tm}}$ is a valid and reliable instrument to assess tactile gnosis after nerve repair.

The model instrument for documentation after nerve repair has been shown to be valid and reliable as a quantitative tool to score nerve repair.
None of the PROMS (PEM, DASH, MHQ, and PRWHE) were considered valid for nerve repair, despite good reliability. In terms of cold sensitivity, three PROMS were considered reliable and valid to assess cold intolerance in nerve repair.

\section{Additional file}

Additional file 1: Appendix: PRISMA checklist. (DOC 62 kb)

\begin{abstract}
Abbreviations
ADL: Activities of daily living; CISS: Cold Intolerance Symptom Severity; CSS: Cold Sensitivity Severity; DASH: Disabilities of the arm, shoulder and hand; DASH-CHNPLAGH: Simple Chinese version of DASH; HAT: Hand assessment tool; ICC: Intraclass correlation coefficient; LOCAL: Area localization; M2PD: Moving two-point discrimination; MHQ: Michigan Hand Outcome Questionnaire; MTT: Manual tactile test; PEM: Patient Evaluation Measure; PRISMA: Preferred Reporting Items for Systematic Reviews and Meta-analysis; PROMS: Patient-reported outcomes measurements; PRWHE: Patient-Rated Wrist and Hand Evaluation; PWES: Potential Work Exposure Scale; RIMH ${ }^{\mathrm{TM}}$ : Rotterdam Intrinsic Hand Myometer; S2PD: Static two-point discrimination; SF12: Health Survey (Short Form 12); STI test $^{\mathrm{TM}}{ }^{\mathrm{S}}$ : Shape and Texture Identification test; WEST: Touch threshold test
\end{abstract}

\begin{abstract}
Acknowledgements
We would like to thank The Brazilian Foundation FAPESP (São Paulo Research Foundation) for supporting the scholarship.
\end{abstract}

\section{Funding}

This work was supported by The Brazilian Foundation FAPESP (São Paulo Research Foundation). Joy MacDermid was supported by a Canadian Institutes of Health Research Chair in Gender, Work and Health and the Dr. James Roth Chair in Musculoskeletal Measurement and Knowledge Translation.

\section{Authors' contributions}

MCRF, EL, and JM contributed to the concept, design, and drafting of the protocol. MCRF, EL, RIB, and AMM participated in the development of the systematic search strategies, and MCRF and EL conducted the review. VMCE, NCS, FPFMR, JM, EL, and MCRF made contributions to the write-up and editing of the manuscript. All authors revised critically and approved the final manuscript.

Ethics approval and consent to participate Not applicable

Consent for publication

Not applicable

\section{Competing interests}

The authors declare that they have no competing interests.

\section{Publisher's Note}

Springer Nature remains neutral with regard to jurisdictional claims in published maps and institutional affiliations.

\section{Author details}

${ }^{1}$ Department of Health Sciences, Ribeirao Preto Medical School, University of Sao Paulo, Ribeirao Preto, SP, Brazil. ${ }^{2}$ Clinical Research, Hand and Upper Limb Centre, St Joseph's Health Centre, Western University, London, ON, Canada. ${ }^{3}$ Rehabilitation and Performance Program, University of São Paulo, Ribeirão Preto, Brazil. ${ }^{4}$ Laboratory of Assessment and Rehabilitation of Locomotor System (LARAL), Federal University of Santa Catarina, Araranguá, SC, Brazil. ${ }^{5}$ Rehabilitation Science, School of Rehabilitation, McMaster University, Hamilton, ON, Canada. 


\section{Received: 4 December 2017 Accepted: 5 October 2018}

Published online: 27 October 2018

\section{References}

1. Jaquet JB, Luijsterburg AJ, Kalmijn S, Kuypers PD, Hofman A, Hovius SE. Median, ulnar, and combined median-ulnar nerve injuries: functional outcome and return to productivity. J Trauma. 2001:51:687-92.

2. Rosberg HE, Carlsson KS, Dahlin LB. Prospective study of patients with injuries to the hand and forearm: costs, function, and general health. Scand J Plast Reconstr Surg Hand Surg. 2005;39:360-9.

3. Fonseca MCR, Mazzer N, Barbieri CH, Elui VMC. Hand injuries: a retrospective study. Rev Bras Ortop. 2006;41:181-6.

4. Trybus M, Lorkowski J, Brongel L, Hladki W. Causes and consequences of hand injuries. Am J Surg. 2006;192:52-7.

5. Saadat S, Eslami V, Rahimi-Movaghar V. Tehran, Iran. The incidence of peripheral nerve injury in trauma patients in Iran. Ulus Travma Acil Cerrahi Derg 2011; 17:539-544

6. Gupta A, Gupta AK, Uppal SK, Mittal RK, Garg R, Aggarwal N. Demographic profile of hand injuries in an industrial town of North India: a review of 436 patients. Indian J Surg. 2013:75:454-61.

7. Dias JJ. Where does surgery for the injured hand figure in the health providers view: an international perspective. Int J Care Injured. 2006; 37:1061-5.

8. Dias JJ, Garcia Elias M. Hand injury costs. Injury. 2006;37:1071-7.

9. Devadoss A, Devadoss S. Hand injuries-still poorly managed. J Hand Microsurg. 2010;2:45-6.

10. Cederlund RI, Ramel E, Rosberg HE, Dahlin LB. Outcome and clinical changes in patients 3, 6, 12 months after a severe or major hand injury can sense of coherence be an indicator for rehabilitation focus? BMC Musculoskelet Disord. 2010;11:286.

11. MacDermid JC. Measurement of health outcomes following tendon and nerve repair. J Hand Ther. 2005;18:297-312.

12. Mafi $P$, Hindocha S, Dhital M, Saleh M. Advances of peripheral nerve repair techniques to improve hand function: a systematic review of literature. Open Orthop J. 2012;6:60-8.

13. Gurbuz H, Aktas S, Calpur OU. Clinical evaluation of ulnar nerve repair at wrist level. Arch Orthop Trauma Surg. 2004;124:49-51.

14. Novak CB, Mackinnon SE. Evaluation of nerve injury and nerve compression in the upper quadrant. J Hand Ther. 2005;18:230-40.

15. Novak CB, Anastakis DJ, Beaton DE, Katz J. Patient-reported outcome after peripheral nerve injury. J Hand Surg. 2009;34A:281-7.

16. Bell-Krotoski J. Sensibility testing: history, instrumentation and clinical procedures. In: Skirven TM, Lee Osterman A, Fedorczyk JM, Amadio PC, editors. Rehabilitation of the hand and upper extremity. 6th ed. St. Louis: Mosby; 2011. Chap. 11

17. Henderson WR, Edin MB. Clinical assessment of peripheral nerve injuries. Lancet. 1948;20:801.

18. Moberg, E. The unsolved problem: How to test the functional value of hand sensibility. J Hand Ther. 1991;4:105-10.

19. Moberg E. Objective methods for determining the functional value of sensibility in the hand. J Bone Joint Surg. 1958;40B:454-76.

20. Dellon AL. A numerical grading scale for peripheral nerve function. J Hand Ther. 1993:6:152-60.

21. Spicher $C$, Kohut MJ. At which stage of sensory recovery can a tingling sign be expected? A review and proposal for standardization and grading. J Hand Ther. 1999;12:298-308.

22. Novak CB. Evaluation of hand sensibility: a review. J Hand Ther. 2001; 14:266-72.

23. Seftchick UL, DeTullio LM, Fedorczyk JM, Aulicino PL. Clinical examination of the hand. In: Skirven TM, Lee Osterman A, Fedorczyk JM, Amadio PC, editors. Rehabilitation of the hand and upper extremity. 6th ed. St. Louis: Mosby; 2011. Chap. 6.

24. Rosén B, Lundborg G. A model instrument for the documentation of outcome after nerve repair. J Hand Surg. 2000;25A:535-43.

25. Lundborg G. Assessment of outcome after nerve repair. Nerve injury and repair. Regeneration, reconstruction and cortical remodeling. 2nd edition. Philadelphia: Elsevier; 2004. p. 248

26. Fess EE. Guidelines for evaluation assessment instruments. J Hand Ther. 1995:8:144-48

27. Bucher C, Hume Kl. Assessment following hand trauma: a review of some commonly employed methods. Brit J Hand Ther. 2002;7:79-84.
28. Vordemvenne T, Langer M, Ochman S, Raschke M, Schult M. Long-term results after primary microsurgical repair of ulnar and median nerve injuries. A comparison of common score systems. Clin Neurol and Neurosurg. 2007; 109:263-71.

29. Lundborg G, Rosén B. Hand function after nerve repair. Acta Physiol. 2007; 189:207-17.

30. MacDermid JC. Outcomes measurement in upper extremity practice. In: Skirven TM, Lee Osterman A, Fedorczyk JM, Amadio PC, editors. Rehabilitation of the hand and upper extremity. 6th ed. St. Louis: Mosby; 2011. Chap. 16.

31. Badalamente M, Coffelt L, Elfar J, et al. Measurement scales in clinical research of the upper extremity, part 2: outcome measures in studies of the hand/wrist and shoulder/elbow. J Hand Surg Am. 2013;38:407-12.

32. Badalamente $M$, Coffelt $L$, Elfar J, et al. Measurement scales in clinical research of the upper extremity, part 1: general principles, measures of general health, pain, and patient satisfaction. J Hand Surg. 2013;38:401-6.

33. MacDermid JC, Stratford P. Applying evidence on outcome measures to hand therapy practice. J Hand Ther. 2004;17:165-73.

34. Law M, MacDermid JC. Evidence-based rehabilitation. 2nd ed; 2008.

35. MacDermid JC. An introduction to evidence-based practice for hand therapists. J Hand Ther. 2004;17:105-17.

36. MacDermid JC, Grewal R, Macintyre NJ. Using an evidence-based approach to measure outcomes in clinical practice. Hand Clin. 2009:25:97-111.

37. De Vet HCW, Aberg M, Ljungberg C, Edin E, Jenmalm P, Millqvist H, Nordh E, Wiberg M. Considerations in evaluating new treatment alternatives following peripheral nerve injuries: a prospective clinical study of methods used to investigate sensory, motor and functional recovery. J Plast Reconst Aest Surg. 2007;60:103-13.

38. Aberg M, Ljungberg C, Edin E, Jenmalm P, Millqvist $H$, Nordh E, Wiberg M Considerations in evaluating new treatment alternatives following peripheral nerve injuries: a prospective clinical study of methods used to investigate sensory, motor and functional recovery. J Plast Reconstr Aesthet Surg. 2007;60:103-13.

39. Scholz T, Krichevsky A, Sumarto A, Jaffurs D, Wirth GA, Paydar K, Evans GR. Peripheral nerve injuries: an international survey of current treatments and future perspectives. J Reconstr Microsurg. 2009;25:339-44.

40. Bear-Lehman J, Colon Abreu B. Evaluating the hand: issues in reliability and validity. Phys Ther. 1989:69:33-41.

41. Kroll W. Reliability theory and research decision in selection of a criterion score. Res Q. 1967:38:412-9.

42. De Vet HCW, Terwee CB, Mokkink LB, Knol DL. Measurement in medicine. A practical guide. Cambridge: Cambridge University Press; 2011. Chap. 7

43. Dowrick SA, Gabbe BJ, Williamson OD, Cameron PA. Outcome instruments for the assessment of the upper extremity following trauma: a review. Injury, Int J Care Injured 2005; 36:468-476.

44. Jerosch-Herold C. Assessment of sensibility after nerve injury and repair: a systematic review of evidence for validity, reliability and responsiveness. J Hand Surg. 2005;30B:252-64

45. Jerosch-Herold C. An evidence-based approach to choosing outcome measures: a checklist for the critical appraisal of validity, reliability and responsiveness studies. Brit J Occup Ther. 2005:68:8.

46. MacDermid JC. Quality appraisal for clinical measurement research reports evaluation form and Intepretation guidelines. In: Evidence-based rehabilitation. Philadelphia: Slack Publishing; 2013. p. 387-8.

47. Jerosch-Herold C. Measuring outcome in median nerve injuries. J Hand Surg. 1993;18:624-8.

48. Schreuders TAR, Roebroeck ME, Jaquet JB, Hovius SER, Stam HJ. Measuring the strength of the intrinsic muscles of the hand in patients with ulnar and median nerve injuries: reliability of the Rotterdam intrinsic hand myometer. J Hand Surg. 2004;29:318-24.

49. Carlsson I, Cederlund R, Hoglund P, Lundborg G, Rosen B. Hand injuries and cold sensitivity: reliability and validity of cold sensitivity questionnaires. Dis \& Rehab. 2008;30:1920-8

50. Dias JJ, Rajan RA, Thompson JR. Which questionnaire is best? The reliability, validity and ease of use of the patient evaluation measure, the disabilities of the arm, shoulder and hand and the Michigan hand outcome measure. J Hand Surg. 2008;33:9-17

51. Chen H, Ji X, Zhang W, Zhang Y, Zhang L, Tang P. Validation of the simplified Chinese (mainland) version of the disability of the arm, shoulder, and hand questionnaire (DASH-CHNPLAGH). J Orthop Surg and Research. 2015;10:1-6. 
52. Naidu SH, Panchik D, Chinchilli VM. Development and validation of the hand assessment tool. J Hand Ther. 2009;22:250-7.

53. Packham T, MacDermid JC. Measurement properties of the patient-rated wrist and hand evaluation: Rasch analysis of responses from a traumatic hand injury population. J Hand Ther. 2013;26:216-24.

54. Jerosch-Herold C, Rosén B, Shepstone L. The reliability and validity of the locognosia test after injuries to peripheral nerves in the hand. J Bone Joint Surg. 2006;88:1048-52.

55. Rosén B, Lundborg G. A new tactile gnosis instrument in sensibility testing. J Hand Ther. 1998;11:251-7.

56. Rosén B. Inter-tester reliability of a tactile gnosis test: the STI-test ${ }^{\text {TM }}$. Brit J Hand Ther. 2003:8:98-101.

57. Jerosch-Herold C. A study of the relative responsiveness of five sensibility tests for assessment of recovery after median nerve injury and repair. J Hand Surg. 2003;28:255-60

58. Hsu H-H, Kuo L-C, Kuan T-S, Yan H-C, Su F-C, Chiu H-Y, Shieh S-J. Determining the functional sensibility of the hand in patients with peripheral nerve repair: feasibility of using a novel manual tactile test for monitoring the progression of nerve regeneration. J Hand Ther. 2017;30:65-73.

59. Rosén B, Jerosch-Herold C. Comparing the responsiveness over time of two tactile gnosis tests: two-point discrimination and the STI-test. Brit J Hand Ther. 2000;5:114-9.

60. Brandsma JW, Schreuders TAR, Birke JA, Piefer A, Oostendorp R. Manual muscle strength testing: intraobserver and interobserver reliabilities for the intrinsic muscles of the hand. J Hand Ther. 1995;8:185-90.

61. Rosén B. Recovery of sensory and motor function after nerve repair. A rationale for evaluation. J Hand Ther. 1996:9:315-27.

62. Watts AMI, Greenstock M, Cole RP. Outcome following the rehabilitation of hand trauma patients. The importance of subjective functional assessment J Hand Surg. 1998;23B:485-9.

63. Lundborg G, Rosèn B. The two-point discrimination test-time for a reappraisal? J Hand Surg. 2004;29B:418-22.

64. Meek MF, Coert JH. Recovery of two-point discrimination function after digital nerve repair in the hand using resorbable FDA- and CE - approved nerve conduits. J Plast Reconst Surg. 2013;66:1307-15.

65. Bell-Krotoski J, Weinstein S, Weinstein C. Testing sensibility, including Touch - Pressure, Two-point Discrimination, Point Localization, and vibration. J Hand Ther. 1993;6:114-123.

66. Sahin F, Atalay NS, Akkaya N, Ercidogan O, Basakci B, Kuran B. The correlation of neurophysiological findings with clinical and functional status in patients following traumatic nerve injury. J Hand Surg. 2014;39B:199-206.

67. Paula MH, Barbosa RI, Marcolino AM, Elui VMC, Rosén B, Fonseca MCR. Early sensory re-education of the hand after peripheral nerve repair based on mirror therapy: a randomized controlled Trial. Braz J Phys Ther. 2016;20:58-65.

68. Bathen M, Gupta R. Basic science of peripheral nerve injury and repair. In: Skirven TM, Lee Osterman A, Fedorczyk JM, Amadio PC, editors. Rehabilitation of the hand and upper extremity. 6th ed. St. Louis: Mosby; 2011. Chap. 42.

69. Callahan AD. Sensibility assessment for nerve lesions in continuity and nerve lacerations. In: Skirven TM, Lee Osterman A, Fedorczyk JM, Amadio PC, editors. Rehabilitation of the hand and upper extremity. 6th ed. St. Louis: Mosby; 2011. Chap. 14.

70. Brandsma JW, Schreuders TA. Sensible manual muscle strength testing to evaluate and monitor strength of the intrinsic muscles of the hand: a commentary. J Hand Ther. 2001;14:273-8.

71. Xu S, Morse AM, Lacy B, Baggett LS, Gogola GR. Peg restrained intrinsic muscle evaluator (PRIME): development, reliability, and normative values of a device to quantify intrinsic hand muscle strength in children. J Hand Surg Am. 2011;36:894-903.

72. Jacquemin GL, Burns SP, Little JW. Measuring hand intrinsic muscle strength: normal values and interrater reliability. J Spinal Cord Med. 2004;27:460-7.

73. Bohannon RW, Andrews AW. Interrater reliability of hand-held dynamometry. Phys Ther. 1987;67:931-3.

74. Shieh SJ, Hsu HY, Kuo LC, Su FC, Chiu HY. Correlation of digital sensibility and precision of pinch force modulation in patients with nerve repair. J Orthop Res. 2011;29:1210-5.

75. Van de Ven-Stevens LA, Munneke M, Terwee CB, Spauwen PH, van der Linde $\mathrm{H}$. Clinimetric properties of instruments to assess activities in patients with hand injury: a systematic review of the literature. Arch Phys Med Reha- bil. 2009;90:151-69.
76. Galanakos SP, Zoubos AB, Johnson EO, Kanellopoulos AD, Soucacos PN. Outcome models in peripheral nerve repair: time for a reappraisal or for a novel? Microsurgery. 2012;32:326-33.

77. Mokkink LB, Prinsen CAC, Bouter LM, de Vet HCW, Terwee CB. The COnsensus-based standards for the selection of health measurement INstruments (COSMIN) and how to select an outcome measurement instrument. Braz J Phys Ther. 2016;20:105-13.

\section{Ready to submit your research? Choose BMC and benefit from:}

- fast, convenient online submission

- thorough peer review by experienced researchers in your field

- rapid publication on acceptance

- support for research data, including large and complex data types

- gold Open Access which fosters wider collaboration and increased citations

- maximum visibility for your research: over $100 \mathrm{M}$ website views per year

At BMC, research is always in progress.

Learn more biomedcentral.com/submissions 